\title{
Evaluation of Carbon Fiber Composites Modified by in Situ Incorporation of Carbon Nanofibers
}

\author{
André Navarro de Miranda $a^{\mathrm{a}}$ Luiz Claudio Pardini ${ }^{\mathrm{b}}$, \\ Carlos Alberto Moreira dos Santos ${ }^{\mathrm{c}}$, Ricardo Vieira ${ }^{\text {a* }}$ \\ ${ }^{a}$ Laboratório de Combustão e Propulsão, Instituto Nacional de Pesquisas Espaciais - INPE, \\ Rod. Presidente Dutra, Km 40, CEP 12630-000, Cachoeira Paulista, SP, Brazil \\ ${ }^{\mathrm{b}}$ Departamento de Ciência e Tecnologia Aeroespacial - DCTA, \\ Instituto de Aeronáutica e Espaço - IAE, \\ Praça Mal. Eduardo Gomes, 50, CEP 12228-904, São José dos Campos, SP, Brazil \\ 'Departamento de Engenharia de Materiais - DEMAR, Escola de Engenharia de Lorena - EEL, \\ Universidade de São Paulo - USP, Pólo-Urbo Industrial, s/n, \\ CEP 12602-810, Lorena, SP, Brazil
}

Received: June 28, 2011; Revised: September 16, 2011

\begin{abstract}
Nano-carbon materials, such as carbon nanotubes and carbon nanofibers, are being thought to be used as multifunctional reinforcement in composites. The growing of carbon nanofiber at the carbon fiber/epoxy interface results in composites having better electrical properties than conventional carbon fiber/epoxy composites. In this work, carbon nanofibers were grown in situ over the surface of a carbon fiber fabric by chemical vapor deposition. Specimens of carbon fiber/nanofiber/epoxy (CF/CNF/epoxy) composites were molded and electrical conductivity was measured. Also, the $\mathrm{CF} / \mathrm{CNF} /$ epoxy composites were tested under flexure and interlaminar shear. The results showed an overall reduction in mechanical properties as a function of added nanofiber, although electrical conductivity increased up to $74 \%$ with the addition of nanofibers. Thus CF/CNF/epoxy composites can be used as electrical dissipation discharge materials.
\end{abstract}

Keywords: carbon nanofibers, epoxy composites, electrical conductivity

\section{Introduction}

Many research efforts have been directed towards producing polymer composites reinforced with carbon nanotubes for functional and structural applications ${ }^{1}$. However, despite their intrinsic high mechanical and thermal properties, even after two decades of research, the full potential of employing carbon nanotubes (CNT) as reinforcements has been severely limited. This was because of the difficulties associated with dispersion of entangled carbon nanotubes during processing and poor interfacial interaction between nanofilaments and polymer matrix ${ }^{1-3}$. Some of the studies suggests, for instance, that carbon nanotube materials increase the shear strength of the composite at the fiber/matrix interface ${ }^{4,5}$.

Presently, there are two main routes ways for adding carbon nanofiller into conventional fiber-reinforced polymeric materials. The first one is by dispersing carbon nanofilaments entirely throughout the polymeric matrix which afterwards is layered with reinforcing fibers. The second route concerns the direct attachment of nano-fillers onto primary reinforcing fibers. These two approaches have been discussed by Qian et al. ${ }^{6}$ regarding the influence of dispersing CNT to the polymeric matrix or directly attaching onto the fiber surface and their influence on mechanical, electrical and thermal properties.

In order to assure that $\mathrm{CNT}$ are effective reinforcements in polymer nanocomposites, proper dispersion and appropriate interfacial adhesion between the nanofilaments and polymer matrix have to be guaranteed. Several techniques have been developed to disperse the CNT in the polymer matrix, such as high speed shear mixing, calendering, ultrasonication, ball milling, stirring, extrusion use of solvent and surfactant ${ }^{1}$. The appropriate choice of an incorporation method or a combination of them, of CNT into a nanocomposite, as well as their processing conditions has to be based on the desired properties. Also, depending on the incorporation method damage of the CNT can occur on different extent and performance of the nanocomposite can be put in threat ${ }^{7}$.

Functionalization of carbon nano-filles is a key issue on composite properties. In order to improve compatibility between nano-fillers and polymeric matrices modification of their surfaces through chemical or physical techniques to produce optimized polymer nanocomposites has been the issue. In this way, adequate dispersion as well as strong interface bond to polymeric matrices can be achieved for a given polymer or application. In CNT, for instance, functionalization can be accomplished by chemical or physical methods. Chemical functionalization is based on the covalent linkage of functional entities onto carbon scaffold of CNT, while physical functionalization is based on using covalent method which can provide useful functional groups onto the CNT surface ${ }^{7-10}$. Despite much work has been done on CNT for composite reinforcement mainly on two phase nanocomposite systems (CNT/epoxy) in order to understand their potential as a single reinforcement, little work has been reported on three phase nanocomposite systems (CNT/carbon fiber fabric/ epoxy $)^{11-14}$.

Despite carbon nanofibers (CNF) have been known for a long time in the nanoparticle reinforcement scenario only recently works have addressed their usage as reinforcement for composites ${ }^{15-18}$. Their chemical similarity to CNT and their unique structure make them an attractive alternative to the existing nano fillers for composite 
reinforcement for composites. The basic difference between CNF and CNT is their exposed surface and their high aspect ratio. Carbon nanotubes have basal planes in their surface whilst carbon nanofibers have been shown to have prismatic planes which may increase mechanical interlocking ${ }^{19,20}$.

This work deals with the direct in situ growth of carbon nanofibers onto a carbon fiber fabric surface by using chemical vapor deposition (CVD) and the investigation of the influence of the deposition process on the mechanical property and electrical properties of nanocomposite thereof. The experimental results showed so far that for the CNF/ carbon fiber fabric/epoxy nanocomposite, having different amounts of CNF, no improvements were achieved on mechanical properties although the electrical properties could be enhanced in relation to the pristine nanocomposite.

\section{Materials and Methods}

\subsection{Growing carbon nanofibers}

The carbon fiber fabric used was a plain weave 3000 filaments per tow, from Hexcel Co. The carbon fiber had a $7.5 \mu \mathrm{m}$ diameter. The material was cut in $110 \times 50 \mathrm{~mm}$ pieces and heat treated at $400{ }^{\circ} \mathrm{C}$ for 1 hour under argon atmosphere to remove the sizing of the carbon fibers. Composites made with unsized carbon fiber fabric was named unsized. The material was then impregnated with an alcoholic solution (50\% ethanol) of $\mathrm{NiNO}_{3} \cdot 6 \mathrm{H}_{2} \mathrm{O}$ (from Acrōs) using the incipient method. Carbon fiber fabric containing 0.6 and $1.4 \% \mathrm{Ni}$ by weight were dried at $110^{\circ} \mathrm{C}$ for 12 hours. The impregnated carbon fiber fabric was fit in a quartz tube reactor and the temperature was set at $670{ }^{\circ} \mathrm{C}\left(10{ }^{\circ} \mathrm{C} / \mathrm{min}\right)$ under argon flow. At $670{ }^{\circ} \mathrm{C}$, the argon flow was replaced by the reaction mixture which had hydrogen and ethane at a 4:1 ratio. The nanofibers were grown onto the surface of carbon fiber fabric for 15 and 30 minutes.

\subsection{Specimen preparation}

The composites were prepared by stacking five plies of nanofiber deposited carbon fiber fabric. The epoxy resin system was based on Araldite MY750/Aradur HY951. The stacked impregnated plies were hot pressed for 24 hours at a pressure of $5.5 \mathrm{MPa}$. The composites exhibited $26 \%$ carbon fiber by volume. The CF/CNF/epoxy composite was trimmed into specimens having appropriate dimensions to characterize mechanical properties. Table 1 shows the experimental set up used in this work. Molded composites using commercial carbon fiber were named as-received.

\subsection{Characterization of composites}

The composite specimens were characterized by 3-point flexure testing (ASTM D790 -10) using a test speed of, and interlaminar shear (ASTM D2344-10) using a test speed of $1.5 \mathrm{~mm} / \mathrm{min}$, using an Instron 1113 universal testing machine. The full scale load cell was $4900 \mathrm{~N}$.

Electrical resistivity was measured using the 4-point methodology. Measurements were taken using a Keithley 6517A Electrometer. Current was applied between zero and $3 \mathrm{~mA}$ at room temperature.

Table 1. Nickel percentage, reaction time and resulted CNF percentage.

\begin{tabular}{cccc}
\hline Experiment & $\% \mathrm{Ni}$ & Reaction time (minutes) & $\%$ CNF \\
\hline 1 & 0.6 & 15 & 0.2 \\
2 & 0.6 & 30 & 1.0 \\
3 & 1.4 & 15 & 0.5 \\
4 & 1.4 & 30 & 2.0 \\
\hline
\end{tabular}

Polarity of the current was inverted in order to account for and subtract effects of the electromotive force due to electrical contacts.

The percentage of impregnated catalyst was measured by Atomic Absorption (PerkinElmer Analyst 300). The amount of nanofibers grown onto the surface of the carbon fiber fabric was estimated by thermogravimetry (TA Instruments SDT Q600) and the morphology

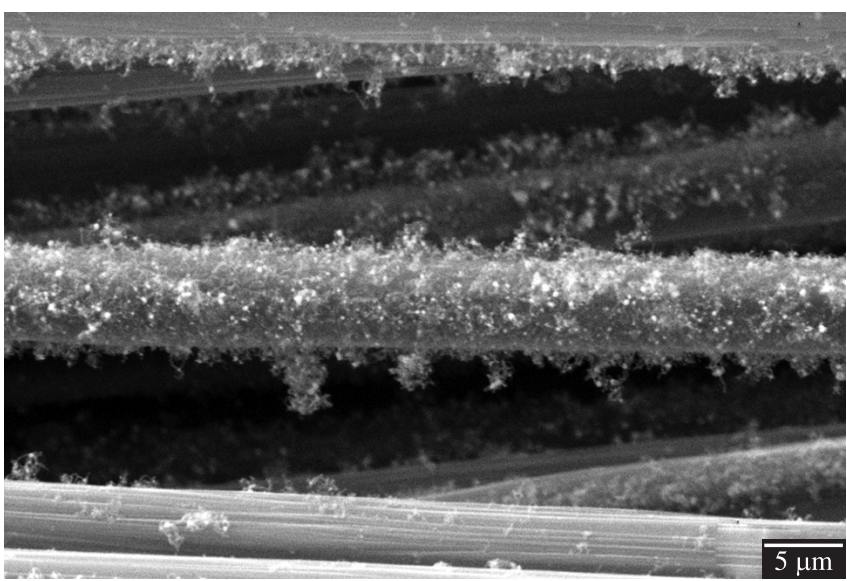

(a)

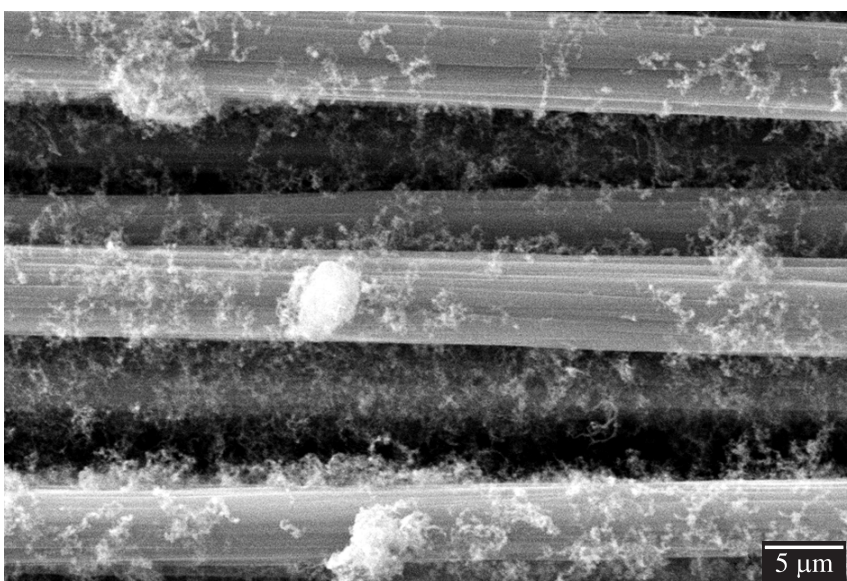

(b)

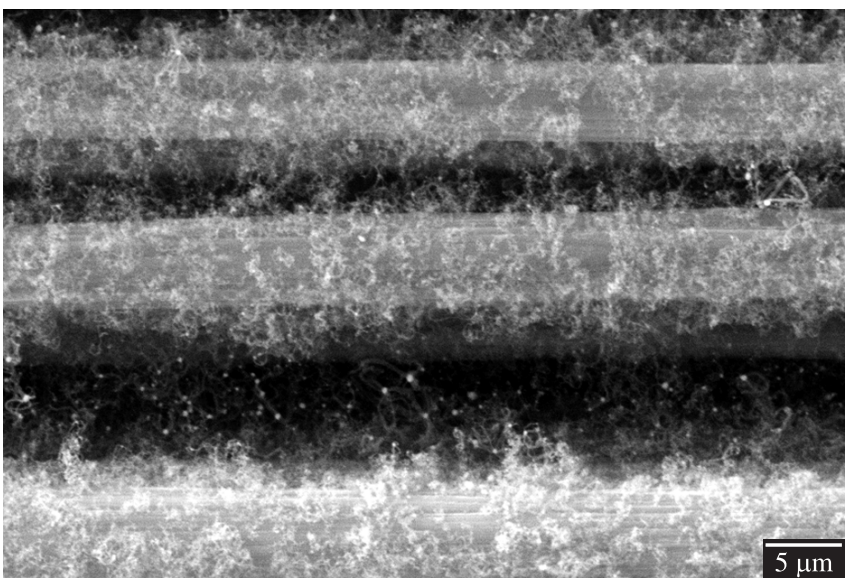

(c)

Figure 1. SEM images of CNF grown over the surface of carbon fibers: a) $0.6 \% \mathrm{Ni} /$ carbon fiber after 15 minutes reaction, b) $1.4 \% \mathrm{Ni} /$ carbon fiber after 15 minutes reaction, c) $1.4 \% \mathrm{Ni}$ /carbon fiber after 30 minutes reaction. 
of the composite was observed by Scanning Electron Microscopy (SEM LEO 440).

\section{Results and Discussion}

The reaction time had a great influence on the growth of carbon nanofibers than the percentage of catalyst impregnated in the carbon fiber fabric. The increase in the percentage of Ni did not improve CNF distribution over the surface of the carbon fiber fabric, as can be seen in Figure 1a, b. Comparing Figures 1b, c, it can be seen that reaction time (growing of $\mathrm{CNF}$ ) favored the distribution of $\mathrm{CNF}$ over the surface of the carbon fiber fabric due to the tip growth type mechanism ${ }^{15}$.

A lower percentage of catalyst tends to reduce the dispersion of $\mathrm{Ni}$ metal, giving rise to more metal particles over the carbon fiber fabric surface which leads to carbon nanofiber entanglements (Figure 1b).

Figure 2 shows results of flexural strength for the composites prepared according to Table 1. Composite were prepared with as-received carbon fiber fabrics and with unsized carbon fiber fabrics (heat treated for sizing removing), for comparison purposes. The heat treatment removes the sizing, leading to composites with lower flexural strength in relation to the pristine ones. However,

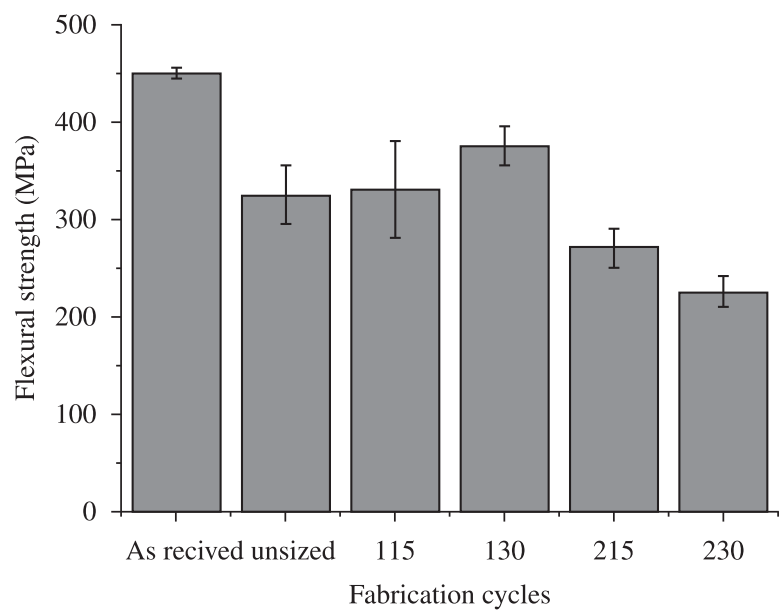

(a)

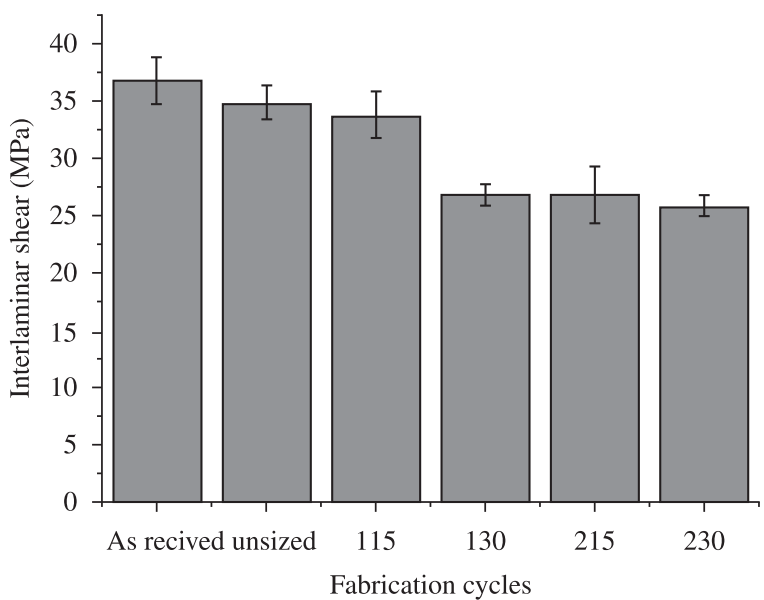

(b)

Figure 2. a) Flexural strength for $\mathrm{CF} / \mathrm{CNF}$ fiber composite using different manufacturing cycles. b) Interlaminar shear strength for CF/CNF composite using different manufacturing cycles. sizing removal is necessary to avoid interference of polymeric vapor decomposition in carbon nanofiber growth while the temperature rose to $670{ }^{\circ} \mathrm{C}$.

Figure $2 \mathrm{a}$ also shows that composites made with unsized carbon fiber fabric and less than $1 \%$ /weight of nanofiber increases the flexural strength to $17 \%$. The increase in the percentage of catalyst also causes loss of flexural strength. Thus, lower amounts of Ni catalyst and higher deposition times favor the growth of carbon nanofibers. The flexural modulus measured for all composites was $31.5 \mathrm{GPa}$, which means that deposition of nanofibers over the surface of carbon fiber fabrics has no influence on the flexural modulus.

Figure $2 b$ shows results for interlaminar shear strength. It can be seen that interlaminar shear strength tends to decrease as the amount of carbon nanofiber increases in the composite. A reduction in the interlaminar shear of composites prepared with carbon nanofiber could be related to the fiber/matrix interaction. Some authors claim that carbon nanofiber can act as a bridge between fibers and matrix in the composite, hindering crack propagation and increasing interlaminar shear. In the present work, pores were formed at the fiber/

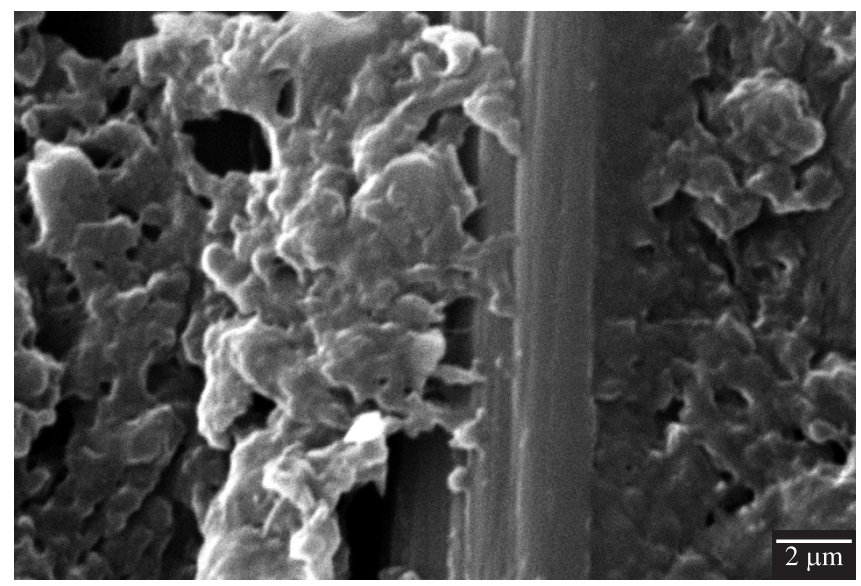

Figure 3. SEM image of pore formation at the $\mathrm{CNF} /$ carbon fiber composite interface.

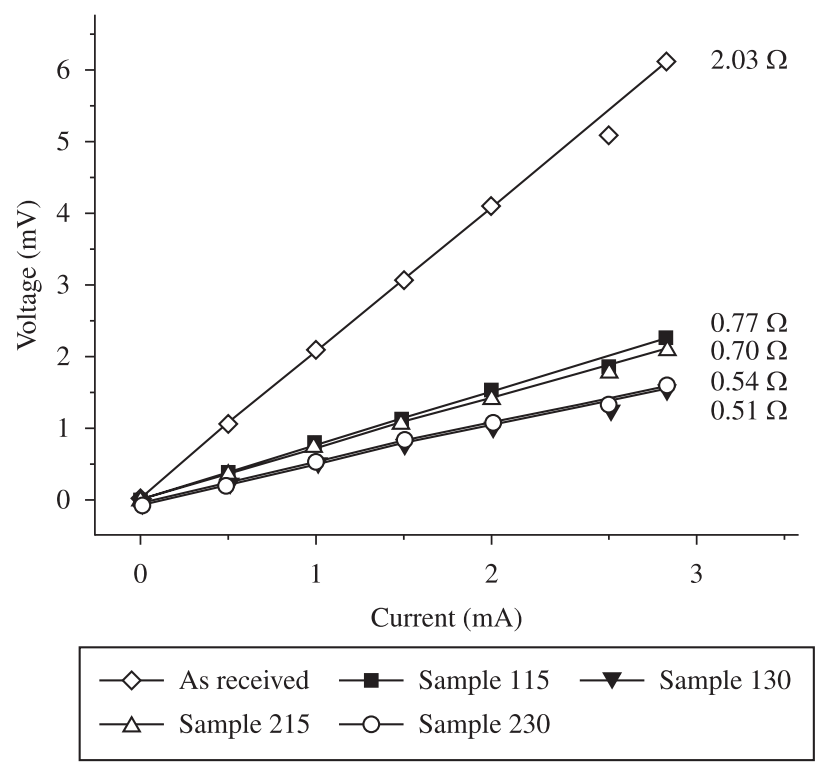

Figure 4. Voltage as a function of electric current for several CNF percentages in the composite. 
matrix interphase (Figure 3) and they were due to the low wettability of the epoxy resin matrix over the $\mathrm{CF} / \mathrm{CNF}$ fabric. Moreover, the epoxy matrix exhibited low interdiffusion in the carbon nanofiber agglomerates, leading to the formation of pores. These pores have an adverse influence on mechanical properties of composites as a whole.

On the other hand, composites made with $\mathrm{CF} / \mathrm{CNF}$ have unique electrical behavior. Figure 4 shows results for voltage as a function of current for composites prepared according to Table 1 . The results show that composites made with the as-received carbon fiber have the highest electrical resistance at room temperature. On the other hand, the higher the content of carbon nanofiber in the composite, the lower is the electrical resistance of the material is. Electrical conductivity of the composite can be enhanced fourfold in relation to the pristine carbon fiber composite just by adding only $1 \%$ /weitght of CNF to it.

Moreover, data from Figure 4 converted to surface electrical resistivity (sheet resistance) can result in values of $0.035 \Omega$ for composite specimens having $1 \% \mathrm{CNF} /$ weight. Amounts higher than $1 \% \mathrm{CNF} /$ weight do not have a significant cost/benefit ratio and can lead to losses in composite mechanical properties.

\section{Conclusions}

Composite materials can be made from carbon nanofibers (CNF) by in situ incorporation of over carbon fiber fabrics through the CVD method, by controlling the percentage of impregnated catalyst and reaction time.

Up to $1 \% \mathrm{CNF} /$ weight can enhance flexural strength of the composite by $17 \%$ when $\mathrm{CNF}$ is deposited over non-sized carbon fiber fabric. However, incorporation of $\mathrm{CNF}$ on composites made of carbon fiber/epoxy can reduce the interlaminar shear. In general, mechanical properties of composites containing CNF can be influenced by micropore formation at the fiber/matrix interface due to the low diffusion of epoxy resin in the CNF agglomerate network. Matrix to fiber interaction is a key factor for composite performance and this issue has to be addressed for future works.

In situ incorporation of CNF over carbon fiber fabric increases the electrical conductivity of composite material made with up to fourfold in relation to the pristine carbon fiber composite, which suggests application of this material for electrical discharge dissipation.

\section{Acknowledgements}

The authors would like to thank FAPESP, Brazil, for support and financial resources.

\section{References}

1. Hussain F, Hojjati M, Okamoto M and Gorga R. Polymer-matrix nanocomposites, processing, manufacturing, and application: An overview. Journal of Composite Materials. 2006; 40(17):1511-1575. http://dx.doi.org/10.1177/0021998306067321

2. Thostenson ET, Ren Z and Chou TW. Advances in the science and technology of carbon nanotubes and their composites: A review. Composites Science and Technology. 2001; 61(13):1899-1912. http://dx.doi.org/10.1016/S0266-3538(01)00094-X

3. Tai NH, Yeh MK and Liu JH. Enhancement of the mechanical properties of carbon nanotube/phenolic composites using a carbon nanotube network as the reinforcement. Carbon. 2004; 42(12-13):2774-2777. http://dx.doi. org/10.1016/j.carbon.2004.06.002
4. Thostenson ET, Li WZ, Wang DZ, Ren ZF and Chou TW. Carbon nanotube/carbon fiber hybrid multiscale composites. Journal of Applied Physics. 2002; 91(9):6034-6037. http://dx.doi.org/10.1063/1.1466880

5. Coleman JN, Khan U, Blau WJ and Gun'ko YK. Small but strong: A review of the mechanical properties of carbon nanotube-polymer composites. Carbon. 2006; 44(9):1624-1652. http://dx.doi.org/10.1016/j. carbon.2006.02.038

6. Qian H, Greenhalgh ES, Shaffer MSP and Bismarck A. Carbon nanotubebased hierarchical composites: A review. Journal of Materials Chemistry. 2010; 20(23):4751-4762. http://dx.doi.org/10.1039/c000041h

7. Ma PC, Siddiqui NA, Marom G and Kim JK. Dispersion and functionalization of carbon nanotubes for polymer-based nanocomposites: A review. Composites Part A: Applied Science and Manufacturing. 2010; 41(10):1345-1367. http://dx.doi.org/10.1016/j.compositesa.2010.07.003

8. Gojny FH and Schulte K. Functionalisation effect on the thermomechanical behavior of multi-wall carbon nanotube/epoxy-composites. Composites Science and Technology. 2004; 64(15):2303-2308. http://dx.doi.org/10.1016/j.compscitech.2004.01.024

9. Kim JA, Seong DG, Kang TJ and Youn JR. Effects of surface modification on rheological and mechanical properties of CNT/epoxy composites. Carbon. 2006; 44(10):1898-1905. http://dx.doi.org/10.1016/j. carbon.2006.02.026

10. Evora MC. Effect of electron beam radiation on the surface and bulk morphology of carbon nanofibers. [Tese]. Ohio: University of Dayton; 2010.

11. Rana S, Alagirusamy R and Joshi M. A review on carbon epoxy nanocomposites. Journal of Reinforced Plastics and Composites. 2009; 28(4):461-487. http://dx.doi.org/10.1177/0731684407085417

12. Lacerda KA. Materiais compósitos baseados em nanotubos de carbono para o setor aeroespacial. [Tese]. Ouro Preto: Universidade Federal de Ouro Preto; 2010.

13. Spitalsky Z, Tasis D, Papagelis K and Galiotis C. Carbon nanotubepolymer composites: Chemistry, processing, mechanical and electrical properties. Progress in Polymer Science. 2010; 35(3):357-401. http://dx.doi.org/10.1016/j.progpolymsci.2009.09.003

14. Garcia EJ, Hart AJ and Wardle BL. Long carbon nanotubes grown on the surface of fibers for hybrid composites. AIAA Journal. 2008; 46(6):1405-1412. http://dx.doi.org/10.2514/1.25004

15. Phamm-Huu C, Vieira R, Louis B, Carvalho A, Amadou J, Dintzer T et al. About the octopus-like growth mechanism of carbon nanofibers over graphite supported nickel catalyst. Journal of Catalysis. 2006; 240(2):194-202. http://dx.doi.org/10.1016/j.jcat.2006.03.017

16. Zou G, Zhang D, Dong C, Li H, Xiong K, Fei L et al. Carbon nanofibers: Synthesis, characterization, and electrochemical properties. Carbon. 2006; 44 (5):828-832. http://dx.doi.org/10.1016/j.carbon.2005.10.035

17. Lim CS, Rodriguez AJ, Guzman ME, Schaefer JD and Minaie B. Processing and properties of polymer composites containing aligned functionalized carbon nanofibers. Carbon. 2011; 49(6):1873-1883. http://dx.doi.org/10.1016/j.carbon.2011.01.010

18. Choi YK, Sugimoto KI, Song SM, Gotoh Y, Ohkoshi Y and Endo M. Mechanical and physical properties of epoxy composites reinforced by vapor grown carbon nanofibers. Carbon. 2005; 43(10):2199-2208. http://dx.doi.org/10.1016/j.carbon.2005.03.036

19. Gulijk C, Lathouder KM and Haswell R. Characterizing herring bone structures in carbon nanofibers using selected area electron diffraction and dark field transmission electron microscopy. Carbon. 2006; 44(14):2950-2956. http://dx.doi.org/10.1016/j.carbon.2006.05.036

20. Tzeng SS, Hung KH and Ko TH. Growth of carbon nanofibers on activated carbon fiber fabrics. Carbon. 2006; 44(5):859-865. http://dx.doi. org/10.1016/j.carbon.2005.10.033 